Supporting Information for

\title{
Titanium-Manganese Compound with Chiral Mn3Ti center
} Relevant to Industrial Olefin Polymerization Catalyst

\author{
Lucjan B. Jerzykiewicz $^{\dagger}$, Józef Utko ${ }^{\dagger}$, Lukasz John ${ }^{\dagger}$, Marek Duczmal ${ }^{\ddagger}$, and Piotr Sobota ${ }^{\dagger *}$ \\ ${ }^{\dagger}$ Faculty of Chemistry University of Wroctaw, \\ 14. F. Joliot Curie, 50-383 Wroctaw, Poland \\ ${ }^{*}$ Technical University of Wroctaw, Faculty of Chemistry, \\ 27, Wyspiańskiego, 50-370 Wroclaw, Poland
}

Index

Notation and formulas

Full Experimental Section S4

Selected X-ray Structural Data S6

Magnetic properties S8 


\section{Notation and formulas}

1

$\left[\mathrm{Mn}_{4}(\mu-\mathrm{Cl}) \mathrm{Cl}_{3}\left(\mathrm{OCH}_{2} \mathrm{CH}_{2} \mathrm{OCH}_{3}\right)_{4}\left(\mathrm{HOCH}_{2} \mathrm{CH}_{2} \mathrm{OCH}_{3}\right)_{3}\right]_{2}{ }^{l}$

$\mathrm{C}_{42} \mathrm{H}_{104} \mathrm{Cl}_{8} \mathrm{Mn}_{8} \mathrm{O}_{28}$

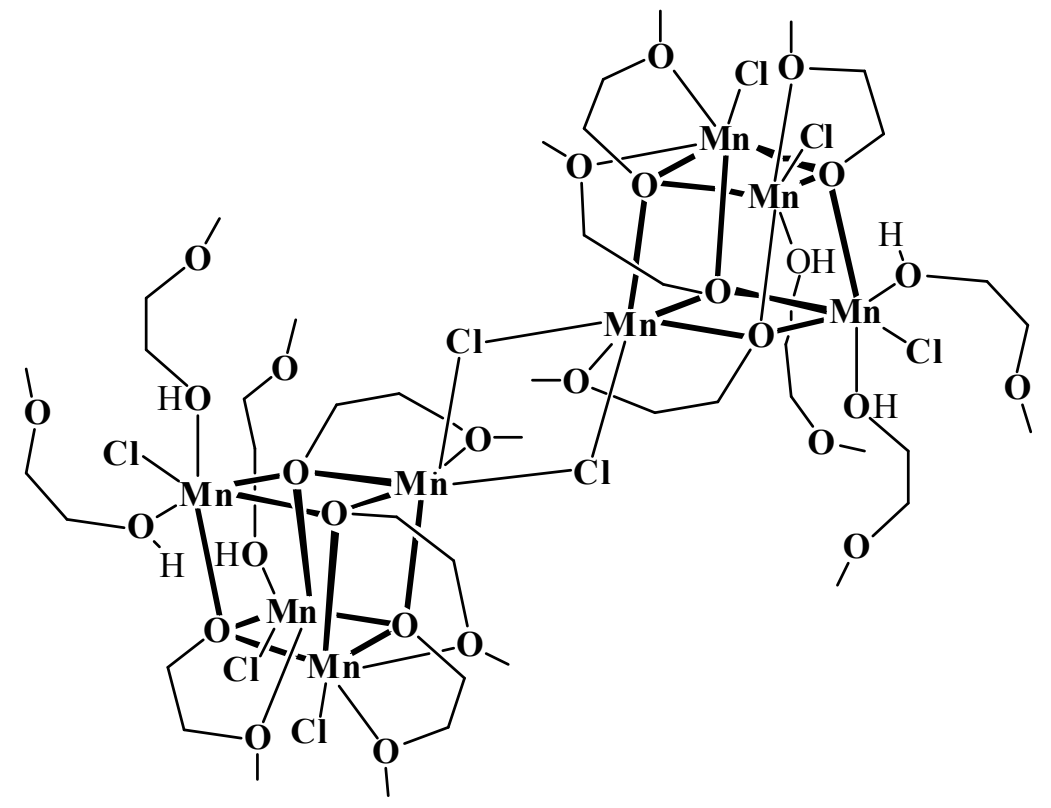

2

$\left[\mathrm{Mn}_{3} \mathrm{Ti}\left(\mu_{3}-\mathrm{OCH}_{2} \mathrm{CH}_{2} \mathrm{OCH}_{3}\right)_{2}\left(\mu_{2}-\mathrm{OCH}_{2} \mathrm{CH}_{2} \mathrm{OCH}_{3}\right)_{3}(\mu-\mathrm{Cl}) \mathrm{Cl}_{2}\left(\mathrm{O}^{\mathrm{i}} \mathrm{Pr}\right)_{2}\right]$ $\mathrm{C}_{21} \mathrm{H}_{49} \mathrm{Cl}_{3} \mathrm{Mn}_{3} \mathrm{O}_{12} \mathrm{Ti}$

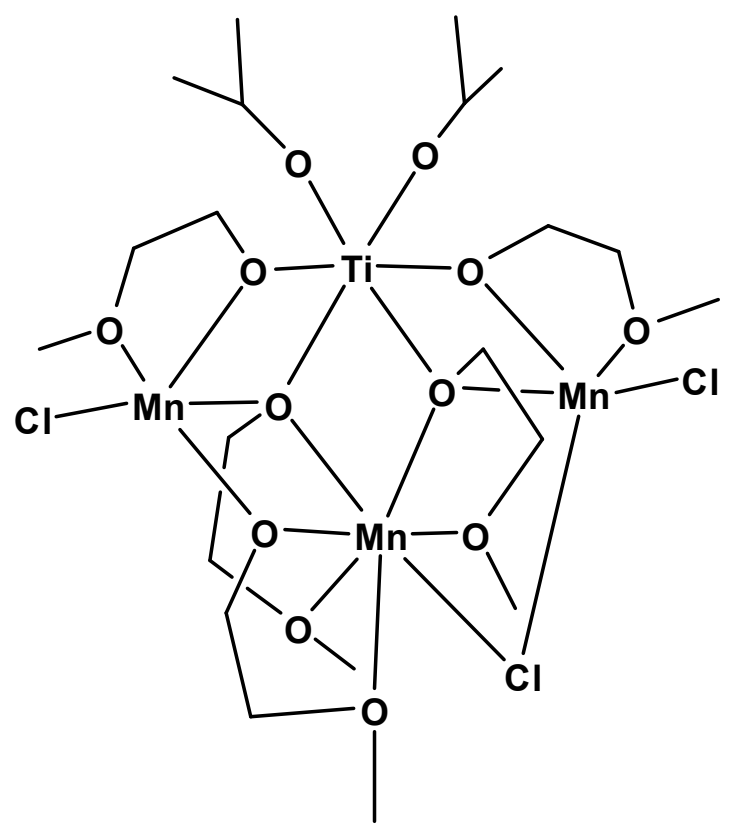




\section{Full Experimental Section}

\section{Preparation of Compounds.}

General: All reactions were conducted under $\mathrm{N}_{2}$ atmospheres. Chemicals were treated as follows: THF, distilled from $\mathrm{CuCl}$, predried over $\mathrm{NaOH}$, and then distilled from $\mathrm{Na} /$ benzophenone; toluene, distilled from $\mathrm{Na}$ /benzophenone; hexanes, distilled from $\mathrm{P}_{2} \mathrm{O}_{5} ; \mathrm{CH}_{3} \mathrm{CN}$, distilled from $\mathrm{CaH}_{2}$, and 2-methoxyethanol (Aldrich) distilled prior to use. Metallic $\mathrm{Mn}$ and $\mathrm{NH}_{4} \mathrm{Cl}$ (Aldrich) used as received. Microanalyses were conducted by ASA-1 (GDR, Karl-Zeiss-Jena) instrument (in-house).

$\mathrm{Mn}_{3} \mathrm{Ti}\left(\mu_{3}-\mathrm{OCH}_{2} \mathrm{CH}_{2} \mathrm{OCH}_{3}\right)_{2}\left(\mu_{2}-\mathrm{OCH}_{2} \mathrm{CH}_{2} \mathrm{OCH}_{3}\right)_{3}\left(\mu-\mathrm{Cl}_{2} \mathrm{Cl}_{2}\left(\mathrm{O}^{\mathrm{i} P r}\right)_{2}\right.$, (2): $1(4.11 \mathrm{~g}, \quad 2.31 \mathrm{mmol})$ and $\mathrm{Ti}\left(\mathrm{O}^{\mathrm{i}} \mathrm{Pr}\right)_{4}(1.75 \mathrm{~g}, 6.16 \mathrm{mmol})$ were dissolved in $\mathrm{C}_{6} \mathrm{H}_{5} \mathrm{CH}_{3}(90 \mathrm{~mL})$. The mixture was stirred for $24 \mathrm{~h}$ at room temperature and filtered off. The filtrate was evaporated to give an oily residue (ca. $20 \mathrm{~mL})$. n-Hexane $(30 \mathrm{~mL})$ was added and the biphasic system was stored at room temperature. After three weeks plate-like colorless crystals of 1 are formed. They were filtered off, washed with n-hexane (3 $10 \mathrm{~mL})$ and dried under vacuum. Yield: $2.61 \mathrm{~g}$; $3.21 \mathrm{mmol}$; (52 \%). Elemental analysis calcd for $\mathrm{C}_{21} \mathrm{H}_{49} \mathrm{Cl}_{3} \mathrm{Mn}_{3} \mathrm{O}_{12}$ Ti: C 31.04, H 6.08; found: C 30.96, H 6.32 . 


\section{X-Ray Structure Determinations.}

Crystal data for $\mathbf{2}$ are given in Table S1, together with refinement details. The crystal of $\mathbf{2}$ was mounted onto a glass fiber and then flash-frozen to $100 \mathrm{~K}$ (Oxford Cryosystem-Cryostream Cooler). Preliminary examination and intensity data collections were carried out on a Kuma KM4CCD $\kappa$-axis diffractometer with graphitemonochromated $\mathrm{Mo} \mathrm{K} \alpha$ radiation. Crystals were positioned $65 \mathrm{~mm}$ from the KM4CCD camera. The data were corrected for Lorentz, polarization and absorption effects. Data reduction and analysis were carried out with the Kuma Diffraction (Wrocław) programs ${ }^{3}$. The structures were solved by direct methods and refined by the fullmatrix least-squares method on all $F^{2}$ data using the SHELXTL programs ${ }^{4}$. The carbon-bonded hydrogen atoms were included in the calculated positions and refined using a riding model. All other hydrogen atoms were located in difference Fourier maps and refined without any restrains.

\section{Magnetic Measurements.}

Magnetic susceptibility in the $1.9-300 \mathrm{~K}$ temperature range and a $0.500 \mathrm{~T}$ were measured with a Quantum Design SQUID magnetometer. 


\section{Selected X-ray Structural Data}

Table S1. X-ray Data Collection and Refinement of the Structures of 2.

Compund

Deposit number

Chemical formula

Formula weight

$\lambda, \AA$

$\mathrm{T}, \mathrm{K}$

Space group

Crystal system

Unit cell dimensions

a, $\AA$

b, $\AA$

c, $\AA$

alpha, ${ }^{\circ}$

beta, ${ }^{\circ}$

gamma, ${ }^{\circ}$

$\mathrm{V}, \AA^{3}$

$\mathrm{Z}$

$\mathrm{D}_{\mathrm{c}}, \mathrm{Mgm}^{-3}$

$\mathrm{F}(000)$

Habit

Crystal size, $\mathrm{mm}$

$\mu, \mathrm{mm}^{-1}$

Absorption correction

Max. and min. transmission

Type of diffractometer

Diffraction geometry

Theta range, ${ }^{\circ}$

Reflections collected

Independent reflections

$\mathrm{R}_{\text {(int) }}$

Observed reflections

Refinement method

Number of parameters

Final $R$ indices $[\mathrm{I}>2 \sigma(\mathrm{I})]$

Final $\mathrm{R}$ indices

(all data)

Goodness-of-fit (S) on $F^{2}$

Largest diff.

peak and hole e. $\AA^{-3}$
2

CCDC 647091

$\mathrm{C}_{21} \mathrm{H}_{49} \mathrm{Cl}_{3} \mathrm{Mn}_{3} \mathrm{O}_{12} \mathrm{Ti}$

812.64

0.71073

100(2)

P $2{ }_{1} / \mathrm{c}$ (No 14)

Monoclinic

19.894(3)

$11.390(3)$

15.798(4)

90

101.91(3)

90

$3502.7(14)$

4

1.541

16821

Block

$0.160 \times 0.119 \times 0.046$

1.555

Analytical

0.684 and 0.865

Kuma KM4CCD

$\kappa$-axis diffractometer

$\omega$

3.14 to 26.50

26179

7241

0.0368

5646 [I $>2 \sigma(\mathrm{I})]$

least-squares on $\mathrm{F}^{2}$

370

$\mathrm{R}_{1}=0.0371$,

$\mathrm{wR}_{2}=0.0853$

$\mathrm{R}_{1}=0.0557$,

$\mathrm{wR}_{2}=0.0904$

1.072

0.749 and -0.396 


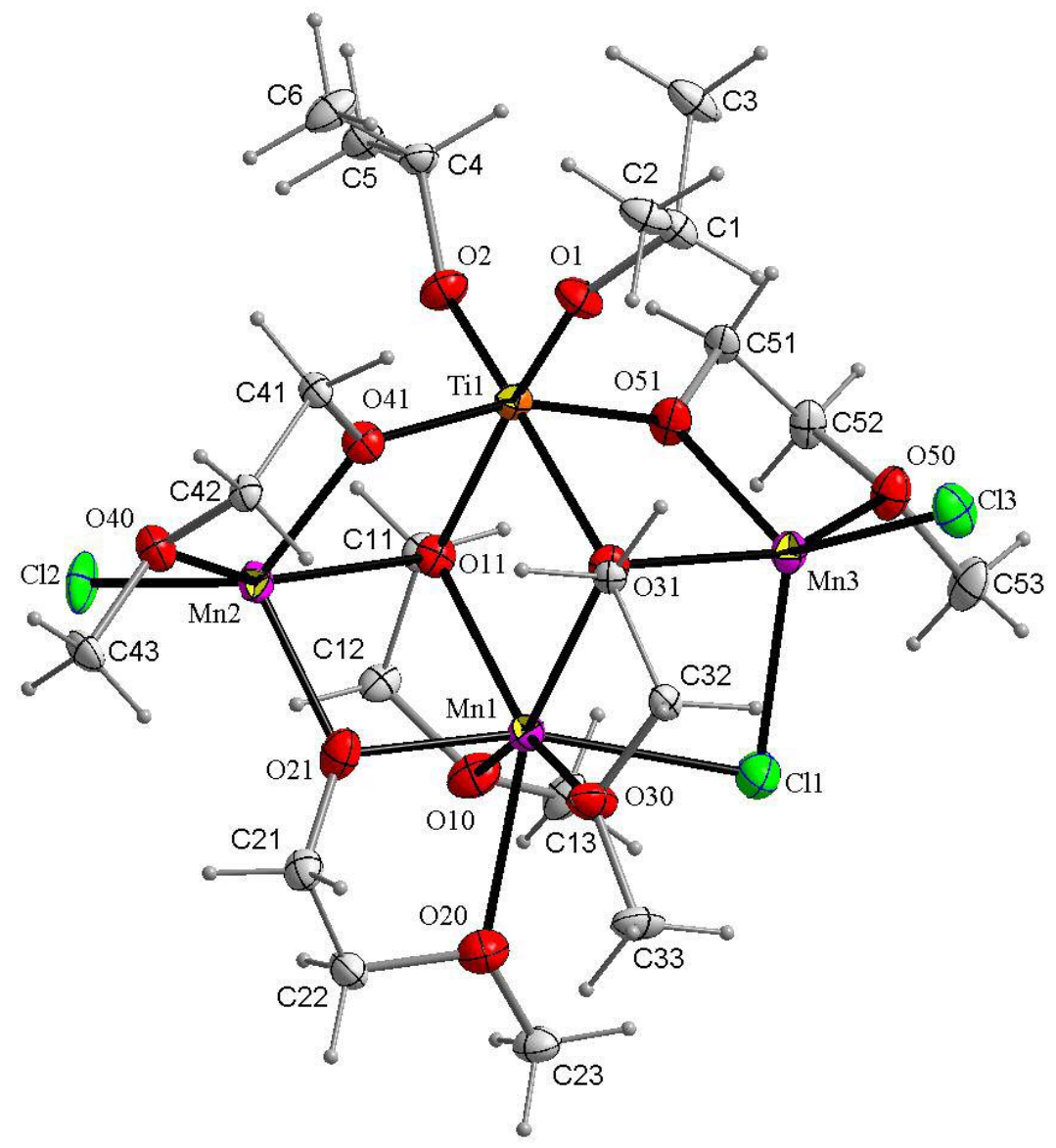

Figure S1. Molecular structure of the 2 (ORTEP plot, thermal ellipsoids set at $50 \%$ for $\mathrm{Mn}, \mathrm{Cl}, \mathrm{O}$ atoms and $30 \%$ for $\mathrm{C}$ atoms). Selected bond lengths and interatomic contacs $[\AA]$ : Mn1-Cl1 2.563(1), Mn2-Cl2 2.325(2), Mn3-Cl1 2.451(2), Mn3-Cl3 2.330(1), Mn1-O11 2.267(2), Mn1-O21 2.103(2), Mn1-O31 2.221(2), Mn2-O11 2.247(2), Mn2-O21 2.058(2), Mn2-O41 2.083(2), Mn3-O31 2.168(2), Mn3-O51 2.066(2), Mn1-O10 2.468(2), Mn1-O20 2.339(2), Mn1-O30 2.474(2), Mn2-O40 2.285(2), Mn3-O50 2.267(2), Ti1-O1 1.783(2), Ti1-O2 1.803(2), Ti1-O11 2.096(2), Ti1-O31 2.175(2), Ti1-O41 1.971(2),

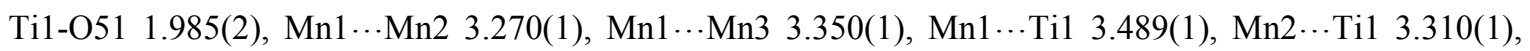

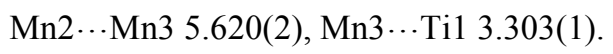




\section{Magnetic properties}

Magnetic susceptibility of complex 2 was measured in the 1.9-300 K temperature range and a $0.500 \mathrm{~T}$ applied field. The results are shown in Figure $\mathrm{S} 2$ in the form of $\mu_{\mathrm{eff}} / 3 \mathrm{Mn}$ vs $T$. The effective magnetic moment decreases from $9.88 \mu_{\mathrm{B}}$ at $300 \mathrm{~K}$ to $5.35 \mu_{\mathrm{B}}$ at $1.9 \mathrm{~K}$. The room temperature $\mu_{\text {eff }}$ value is a little smaller then the expected value for three uncoupled $\mathrm{Mn}$ (II) ions $\left(10.25 \mu_{\mathrm{B}}, g=2.00\right)$. This is indicative of weak antiferromagnetic interactions between the manganese ions.

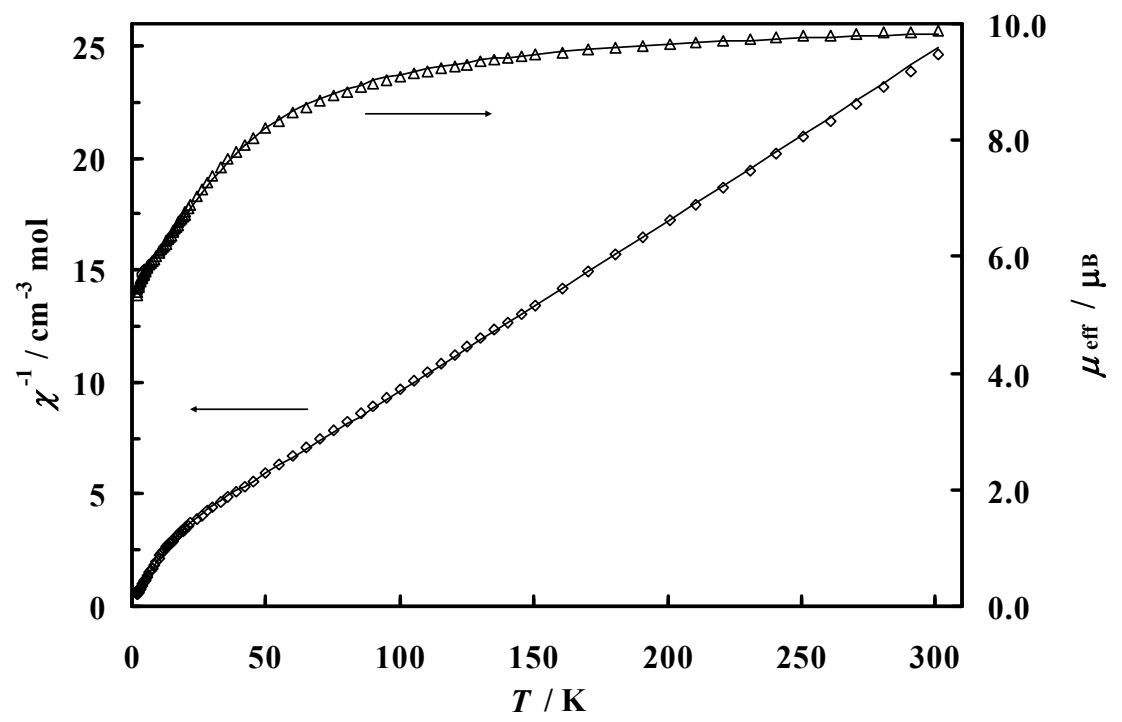

Figure S2. Variation of $\chi^{-1}$ (diamonds) and $\mu_{\mathrm{eff}}$ (triangles) per $\mathrm{Mn}_{3}$ trimer with temperature. The solid lines represent the fit of the $10-300 \mathrm{~K}$ data to the Kambe model with $J_{12}=-2.1$ $\mathrm{cm}^{-1}, J_{23}=0.55 \mathrm{~cm}^{-1}, g=1.99$ (see text for details).

In order to fit the experimental data the Kambe vector coupling method ${ }^{5}$ was applied. Even though the exact symmetry of $\mathrm{Mn}_{3}$ cluster is only $C_{s}$, the reasonable simplifying approximation is possible by taking equal $\mathrm{Mn} 1-\mathrm{Mn} 2$ and $\mathrm{Mn} 1-\mathrm{Mn} 3$ magnetic interactions (Figure S1). Assuming $D_{2 h}$ symmetry of the manganese trimer (isosceles triangle), the Heisenberg spin Hamiltonian can be written as:

$$
H=-2 J_{12}\left(\mathbf{S}_{1} \cdot \mathbf{S}_{2}+\mathbf{S}_{1} \cdot \mathbf{S}_{3}\right)-2 J_{23} \mathbf{S}_{2} \cdot \mathbf{S}_{3},
$$

where $\mathbf{S}_{\mathrm{i}}$ is the spin of the Mn ion number $i$ in Figure S1. Defining $\mathbf{S}_{23}=\mathbf{S}_{2}+\mathbf{S}_{3}$ and $\mathbf{S}=\mathbf{S}_{23}+$ $\mathbf{S}_{1}$, one obtains 27 coupled spin states, which energies are given by:

$$
E\left(S_{23}, S\right)=-J_{12}\left[S(S+1)-S_{23}\left(S_{23}+1\right)-35 / 4\right]-J_{23}\left[S_{23}\left(S_{23}+1\right)-35 / 2\right] .
$$

The best fit (the solid line in Figure S2) of the experimental $\mu_{\mathrm{eff}}$ data to the theoretical model was obtained with $J_{12}=-2.1 \mathrm{~cm}^{-1}, J_{23}=0.55 \mathrm{~cm}^{-1}, g=1.99$, and the temperature independent 
paramagnetism $N \alpha$ fixed at 0 (the agreement factor $R=\Sigma\left[(\chi T)_{\exp }-(\chi T)_{\text {calc }}\right]^{2} / \Sigma\left[(\chi T)_{\exp }\right]^{2}=$ $\left.6.0 \cdot 10^{-5}\right)$. The ground state is found to be $\mid S_{23}=5, S=5 / 2>$, the first excited state is $\mid S_{23}=4, S$ $=3 / 2>$ at $12.9 \mathrm{~cm}^{-1}$, and the second $\mid S_{23}=5, S=7 / 2>$ at $14.7 \mathrm{~cm}^{-1}$. Only data above $10 \mathrm{~K}$ were employed in the fitting procedure since the decrease of $\mu_{\text {eff }}$ below $10 \mathrm{~K}$ (see Figure S4) is likely due to zero-field splitting (ZFS) and intermolecular exchange interactions which are not incorporated in the theoretical model. Considering the relatively short distance between the trinuclear manganese clusters along the $b$ crystallographic axis ( $d(\operatorname{Mn} 2-\operatorname{Mn} 3[x, 1+y, z])$ $=6.6277(17) \AA$ ), we have tried to include intertrimer exchange in a molecular field approximation. ${ }^{6}$ As a result the agreement factor $R$ decreases by $0.6 \%$ which clearly demonstrates the lack of an effective exchange pathway between the magnetic clusters. $\{\ldots$ dysk. strukt. ... $\}$ The $J$ and $g$ parameters for $\{\mathbf{X}\}$ are typical of Mn(II) trimers, though most of them are linear (Table S2).

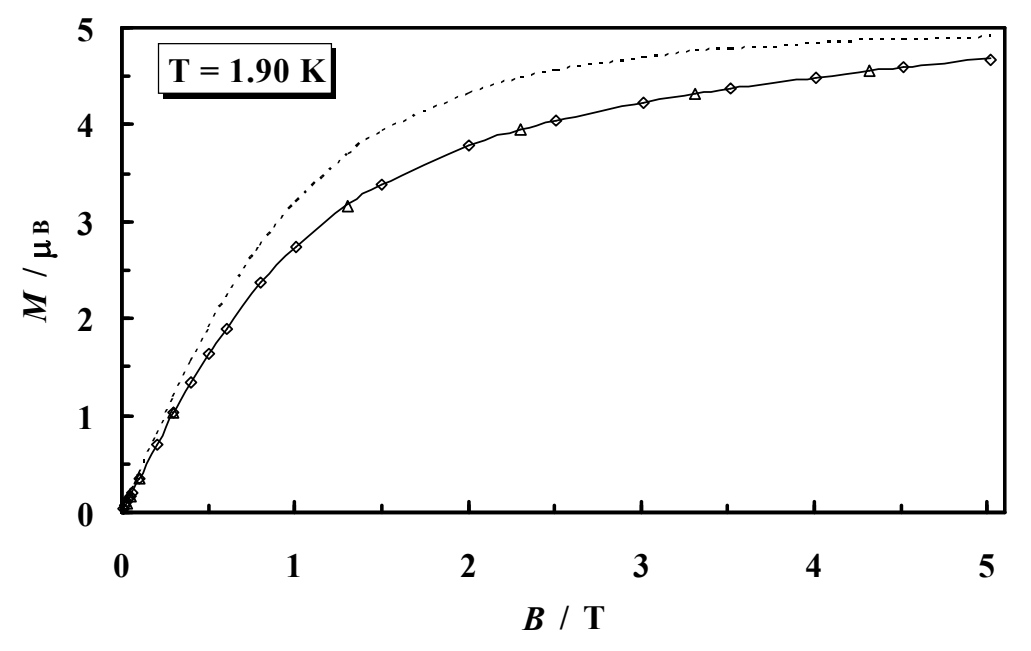

Figure S3. Field dependence of magnetization for $\{\mathbf{X}\}$ at $1.90 \mathrm{~K}$ (increasing field diamonds, decreasing field - triangles). The solid line is calculated for $S=5 / 2$ isolated ground term with the ZFS parameters: $D=0.40 \mathrm{~cm}^{-1}, E=0.15 \mathrm{~cm}^{-1}, B_{4}{ }^{0}=8.4 \cdot 10^{-3} \mathrm{~cm}^{-1}$ and $g=1.99$ (fixed). The broken curve is calculated with the parameters obtained within the Kambe model (see Figure S2 caption and text); it is almost identical to the $S=5 / 2$ Brillouin function.

To confirm the $S=5 / 2$ ground state and to estimate ZFS parameters, low-temperature magnetization was measured up to $5 \mathrm{~T}$ (Figure S3). Using the method described by Belorizky ${ }^{7}$ we calculated the field dependent magnetization allowing all spin states to be populated. The broken line in Figure S3 represents the theoretical curve with $J_{12}, J_{23}$ and $g$ parameters obtained earlier from the fitting of $\chi(T)$. Since the excited states are lying more than $12.9 \mathrm{~cm}^{-1}$ $(18.6 \mathrm{~K})$ above the ground state, only the $\mid S_{23}=5, S=5 / 2>$ state is accessible at $1.9 \mathrm{~K}$. As a result the broken line in Figure S3 closely coincides with the $S=5 / 2$ Brillouin function $(g=$ 1.99). As intermolecular exchange was acknowledged to be weak, the main source of the 
discrepancy of the calculated and the experimental points remains crystal field interaction. Assuming that only the ground state is populated, we have calculated magnetization by the full matrix diagonalization of the spin Hamiltonian:

$$
\boldsymbol{H}=\mu_{B} B \cdot \boldsymbol{g} \cdot \boldsymbol{S}+D\left[\boldsymbol{S}_{\mathrm{z}}^{2}-1 / 3 \cdot S(S+1)\right]+E\left(\boldsymbol{S}_{\mathrm{x}}{ }^{2}-\boldsymbol{S}_{\mathrm{y}}{ }^{2}\right),
$$

where $S=5 / 2, D$ and $E$ are the second order ZFS parameters and the isotropic $g$ value was fixed at 1.99. After several trials it turned out that adding the fourth order ZFS term $B_{4}{ }^{0} \boldsymbol{O}_{4}{ }^{0}$ considerably improves the fitting. Fourth order crystal field terms are usually taken into consideration in analysis of EPR spectra (see for example ${ }^{8}$ ) but rarely in interpretation of magnetization. The best fit (solid line in Figure S3) of the experimental $M(B)$ data to the theoretical model was obtained with $D=0.40 \mathrm{~cm}^{-1}, E=0.15 \mathrm{~cm}^{-1}, B_{4}{ }^{0}=8.4 \cdot 10^{-3} \mathrm{~cm}^{-1}$. Figure S4 shows the low-temperature effective magnetic moment of $\{\mathbf{X}\}$ calculated with this set of parameters (solid line). It is seen that below $5 \mathrm{~K}$ the theoretical line fairly well simulates the experimental curve. The values of the ZFS parameters are similar to those obtained for Mn(II) trimers (Table $\{\mathrm{S} 2\})$, but the collection of reference complexes is rather limited.

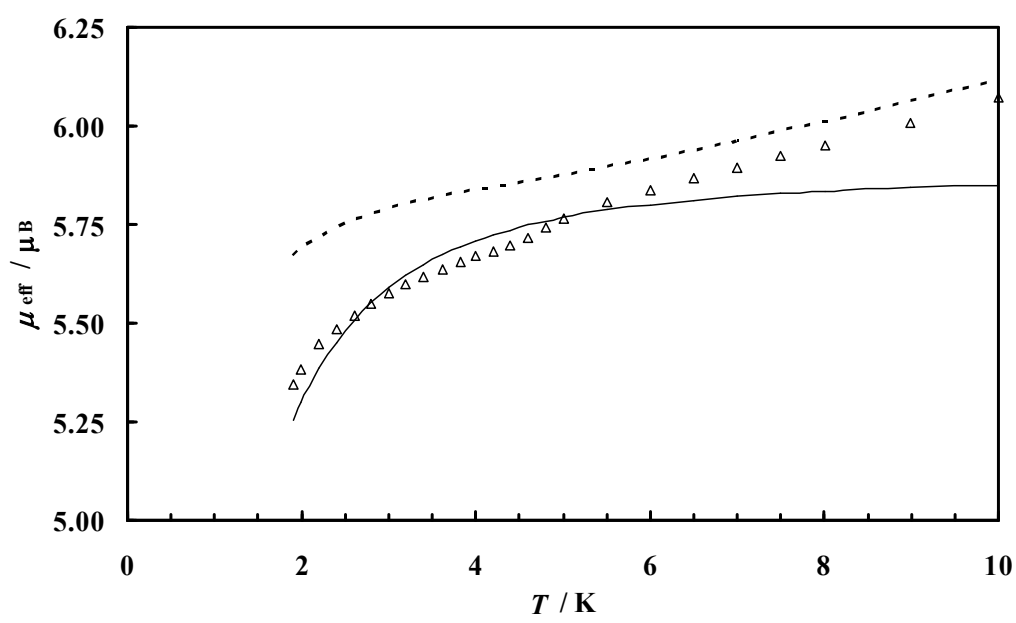

Figure S4. The low-temperature part of the $\mu_{\mathrm{eff}}(T)$ plot (triangles). The solid line is calculated with the ZFS parameters for $S=5 / 2$ isolated ground term - see Figure S3 caption and the text. The broken line is extrapolated from the best fit to the Kambe model at 10-300 K temperature range (Figure S2). 
Table S2. Comparison of magnetic data for Mn(II) trimers.*

\begin{tabular}{|c|c|c|c|c|c|}
\hline Complex & Cluster geometry & $\begin{array}{c}d(\mathrm{Mn} 1-\mathrm{Mn} 2) \\
(\AA)\end{array}$ & $S$ & Magnetic parameters $\left(\mathrm{cm}^{-1}\right)$ & Reference \\
\hline 2 & triangle & 3.310 (av.) & $5 / 2$ & $\begin{array}{l}J_{12}=-2.1, J_{23}=0.55 \\
D=0.53, B_{4}^{0}=0.011\end{array}$ & this work \\
\hline$\left[\mathrm{Mn}_{3}(\mathrm{ac})_{6}(\mathrm{bpy})_{2}\right]$ & linear & $3.614(1)$ & $5 / 2$ & $J_{12}=-2.2, J_{23}=-0.09$ & 9 \\
\hline$\left[\mathrm{Mn}_{3}(\mathrm{ac})_{6}(\mathrm{biphme})_{2}\right]$ & linear & $3.700(2)$ & $5 / 2$ & $J_{12}=-2.8, J_{23}=-0.311$ & 10 \\
\hline$\left[\mathrm{Mn}_{3}(\mathrm{ac})_{2}(\mathrm{bpc})_{2}(\mathrm{py})_{4}\left(\mathrm{H}_{2} \mathrm{O}\right)_{2}\right]$ & linear & $3.289(4)$ & $5 / 2$ & $J_{12}=-1.43$ & 11 \\
\hline$\left[\mathrm{Mn}_{3}(\mathrm{ac})_{6}(\mathrm{pybim})_{2}\right]$ & linear & 3.558 & $5 / 2$ & $J_{12}=-1.9, z J^{\prime}=-0.1$ & 12 \\
\hline$\left[\mathrm{Mn}_{3}(\mathrm{ac})_{3}\left(\mu_{3}-\mathrm{OH}\right)(\mathrm{cat})(\mathrm{py})_{5}\right]$ & isosceles triangle & 3.156 (av.) & $1 / 2$ & $J_{12}=-2.36, J_{23}=-1.92$ & 13 \\
\hline$\left(\mathrm{C}_{2} \mathrm{H}_{10} \mathrm{~N}_{2}\right)\left[\mathrm{Mn}_{3}\left(\mathrm{HPO}_{3}\right)_{4}\right]$ & linear & $2.999(1)$ & $5 / 2$ & $J_{12}=-8.5$ & 14 \\
\hline $\mathrm{Mn}_{3}\left(\mathrm{H}_{2} \mathrm{O}\right)_{6} \mathrm{Ga}_{4}\left(\mathrm{PO}_{4}\right)_{6}$ & linear & 3.310 & $5 / 2$ & $J_{12}=-1.7$ & 15 \\
\hline$\left(\mathrm{C}_{3} \mathrm{H}_{12} \mathrm{~N}_{2}\right)\left[\mathrm{Mn}_{3}\left(\mathrm{HPO}_{3}\right)_{4}\right]$ & linear & $3.001(1)$ & $5 / 2$ & $J_{12}=-7.5$ & 16 \\
\hline$\left[\mathrm{Mn}_{3}\left(\mu-\mathrm{ClCH}_{2} \mathrm{COO}\right)_{6}(\mathrm{bpy})_{2}\right]$ & linear & $3.624(1)$ & $5 / 2$ & $\begin{array}{c}J_{12}=-1.9, \\
D=-0.16, E=-0.015\end{array}$ & 17 \\
\hline $\mathrm{Na}_{12}\left[\mathrm{Mn}_{3}\left(\mathrm{H}_{2} \mathrm{O}\right)_{3}\left(\mathrm{BiW}_{9} \mathrm{O}_{33}\right)_{2}\right] \cdot 43 \mathrm{H}_{2} \mathrm{O}$ & $\begin{array}{c}\text { equilateral } \\
\text { triangle }\end{array}$ & $>4.2$ & $\begin{array}{c}1 / 2 \\
7 / 2 \text { admix. }\end{array}$ & $\begin{array}{c}J=-1.04 \\
D=-0.381, E=0.054\end{array}$ & 18 \\
\hline$\left[\mathrm{Mn}_{3}\left(\left(\mathrm{CH}_{3}\right)_{2} \mathrm{CHCOO}\right)_{6}(\text { phen })_{2}\right]$ & linear & $3.5312(3)$ & $5 / 2$ & $J_{12}=-1.61$ & 19 \\
\hline$\left[\mathrm{Mn}_{3}\left(\left(\mathrm{CH}_{3}\right)_{2} \mathrm{CHCOO}\right)_{6}(\mathrm{bpy})_{2}\right]$ & linear & $3.4894(3)$ & $5 / 2$ & $J_{12}=-1.86$ & 19 \\
\hline
\end{tabular}


*Abbreviations: $\mathrm{ac}=$ acetato(1-); bpy = 2,2'-bipyridine; biphme = methoxy-bis $\left(1\right.$-methylimidazol-2-yl)phenylmethane; $\mathrm{H}_{2}$ bpc $=2,2$ 'bipyridyl-3,3'-dicarboxylic acid; py = pyridine; rybim = 2-(2-pyridyl)benzimidazol; $\mathrm{H}_{2}$ cat = catechole; $\mathrm{C}_{2} \mathrm{H}_{10} \mathrm{~N}_{2}=$ ethylenediammonium $(2+) ; \mathrm{C}_{3} \mathrm{H}_{12} \mathrm{~N}_{2}=$ propanediammonium $(2+)$; phen = 1,10-phenanthroline.

${ }^{l}$ Jerzykiewicz, L. B.; Utko, J.; M. Duczmal, Sobota, P. Dalton Trans. 2007, 825.

${ }^{2}$ Jerzykiewicz, L. B.; Utko, J.; Sobota, P. Oragnometallics 2006, 25, 4024.

${ }^{3}$ Oxford Diffraction (2004). CrysAlis CCD and CrysAlis RED. Versions 1.171. Oxford Diffraction Ltd, Abingdon, Oxfordshire, England.

4 Sheldrick, G. M. (1998). SHELXTL. Version 5.1. Bruker AXS Inc., Madison, Wisconsin, USA.

${ }^{5}$ K. Kambe, J. Phys. Soc. Japan 1950, 15, 48.

${ }^{6}$ A.P. Ginsberg, R.L. Martin, R.W. Brookes, R.C. Sherwood, Inorg. Chem. 1972, 11, 2284.

${ }^{7}$ E. Belorizky, P.H. Fries, E. Gojon, J.-M. Latour, Mol. Phys. 1987, 61, 661.

${ }^{8}$ E.A. Buvaylo, V.N. Kokozay, O.Yu. Vassilyeva, B.W. Skelton, J. Jezierska, L.C. Brunel, A. Ozarowski, Inorg. Chem. 2005, 44, 206.

${ }^{9}$ S. Ménage, S.E. Vitols, P. Bergerat, E. Codjovi, O. Kahn, J.-J. Girerd, M. Guillot, X. Solans, T. Calvet, Inorg. Chem. 1991, $30,2666$.

${ }^{10}$ R.L. Rardin, P. Poganiuch, A. Bino, D.P. Golgberg, W.B. Tolman, S. Liu, S.J. Lippard, J. Am. Chem. Soc. 1992, 114, 5240.

${ }^{11}$ Z.J. Zhong, X.-Z. You, T.C.W. Mak Polyhedron 1994, 13, 2157.

${ }^{12}$ V. Tangoulis, D.A. Malamatari, K. Soulti, V. Stergiou, C.P. Raptopoulou, A. Terzis, T.A. Kabanos, D.P. Kessissoglou, Inorg. Chem. 1996, $35,4974$.

${ }^{13}$ R.A. Reynolds, W.O. Yu, W.R. Dunham, D. Coucouvanis, Inorg. Chem. 1996, 35, 2721.

${ }^{14}$ S. Fernández, J.L. Mesa, J.L. Pizarro, L. Lezama, M.I. Arriortua, R. Olazcuaga, T. Rojo, Chem. Mater. 2000, 12, 2092.

${ }^{15}$ K.F. Hsu, S.L. Wang, Inorg. Chem. 2000, 39, 1773.

${ }^{16}$ S. Fernández, J.L. Mesa, J.L. Pizarro, L. Lezama, M.I. Arriortua, R. Olazcuaga, T. Rojo, Chem. Mater. 2000, 12, 2092.

${ }^{17}$ G. Fernández, M. Corbella, J. Mahía, M.A. Maestro, Eur. J. Inorg. Chem. 2002, 2502.

${ }^{18}$ L. David, C. Crăciun, V. Chis, R. Tetean, Solid State Commun. 2002, 121, 675.

${ }^{19}$ S.G. Baca, Y. Sevryugina, R. Clérac, I. Malaestean, N. Garbeleu, M.A. Petrukhina, Inorg. Chem. Commun. 2005, 8, 474. 